\title{
CORRELATION OF MISSING OUT (FOMO), ANXIETY AND AGGRESSION OF YOUNG ADULTS
}

\author{
Priyanka Kacker ${ }^{*}{ }^{凶}$, Saket Saurav ${ }^{2}$ \\ ${ }^{1}$ Assistant Professor, Institute of Behavior Science, Gujarat Forensic Sciences University, India \\ 2 Student, Institute of Behavior Science, Gujarat Forensic Sciences University, India
}

DOI: https://doi.org/10.29121/granthaalayah.v8.i5.2020.107

Article Type: Research Article

Article Citation: Priyanka Kacker, and Saket Saurav. (2020). CORRELATION OF MISSING OUT (FOMO), ANXIETY AND AGGRESSION OF YOUNG ADULTS. International Journal of Research GRANTHAALAYAH, 8(5), 132-138. https://doi.org/10.29121/granthaa layah.v8.i5.2020.107

Received Date: 18 May 2020

Accepted Date: 31 May 2020

Keywords:

FoMo

Social Media Addiction

Anxiety

Depression

\section{ABSTRACT}

Social media now has become integral part of human race. It not only helps in knowing about the opportunity one has online but also offline. On the upside, these resources provide multiple opportunities for interaction; on the downside, they often give us more than required amount of options that often lead to confusion and distress and have practical restrictions. The use of social media is so prevalent that it is leading society towards cyber distress. Thus, this study attempts to study the correlation between FoMo, Social Media Addiction, Personal Relationship, Aggression Factor one, two, three and four and Anxiety. A total of 600 sample population was selected for this purpose and a total of 60 sample (30- Neutral group and 30- High score Group) for study of brain electrical wave pattern. The tool used in this study was FoMo and Social Media Addiction Questionnaire, Personal Relationship Questionnaire, Buss and Perry aggression scale and Zung Anxiety scale. The result reveals that there is a positive significant correlation between FoMo, Social Media Addiction and Psychological Factors at $(\mathrm{p}<0.001$ and $\mathrm{p}<0.005)$.

\section{INTRODUCTION}

\subsection{FEAR OF MISSING OUT (FOMO)}

FoMo refers to the uneasy and often all-consuming sense that friends or others are having rewarding experiences from which one is absent [1], [2], [3], [4], [5]. It is characterized by a desire to remain socially connected and may manifest itself as a form of social anxiety [3],[4], [5], [6] and has been linked to low levels of mood and life satisfaction [6].

FoMo appears to be a universal phenomenon across cultures. For example, the word kiasu originating from the Hokkien (Chinese) dialect, is generally translated as the "fear of missing out" or the fear of losing out to someone else While FoMo has garnered widespread attention in the media for several years [5],[6], it has only recently come under the scrutiny of academic researchers [8],[10]Drawing upon the framework of Self-Determination theory [9], to date, the literature has predominantly focused on FoMo as a mediator, linking deficits in psychological needs to negative social networking use [8] and academic motivational styles [10]. More specifically, these studies have found that those higher in FoMo tend to have an unhealthy relationship with social networking sites [10]. For example, these people are more likely to check text messages while driving and use Facebook immediately upon waking,

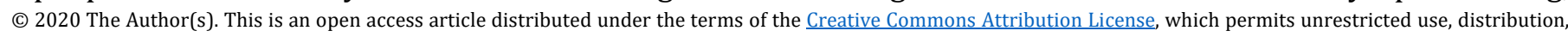
and reproduction in any medium, provided the original author and source are credited. 
directly before going to sleep, and during college lectures [10]. However, FoMO may have implications beyond social networking or social media use and academic motivation.

Wanting to be socially connected, a desire to know what others are doing and to be a part of rewarding experiences is a basic human need present from infancy and is therefore not restricted to social media use. However, the options for connecting, sharing, and having rewarding experiences with acquaintances have increased considerably due to the permanent accessibility of social media via portable devices.

Fear of missing out is described as «(...) a pervasive apprehension that others might be having rewarding experiences from which one is absent (...)» and «(...) a desire to stay continually connected with what others are doing» (Przybylski et al., 2013, p.1). Although FoMO is not necessarily a phenomenon exclusive to social media users, individuals with high FoMO might feel compelled to check their social media more often. to keep up to date on their friends' plans and activities. Frequent use of social media may also trigger or increase this fear of missing out, because of the individual's heightened awareness of the numerous possibilities for interaction. Przybylski was the first to present an operationalized and empirically-based account of the FoMO phenomenon, together with a selfreport questionnaire - the FoMO scale (FoMO), published in a study that also gathered empirical evidence of the concept's construct validity and psychological correlates (Przybylski et al., 2013). According to these authors, the scale is meant to reflect the fears and worries people may have in relation to being out of touch with experiences across their extended social environment.

\subsection{SOCIAL MEDIA USE}

FoMO relates to social media use both in its experience and origins (e.g., J. Walter Thompson Intelligence, 2011, 2012); thus, research on social media use is important to consider in the current investigation. With the increase in social media use over the last decade, parents and researchers have become concerned over whether social media use may harm more than it may help, perpetuating a host of research investigations related to negative consequences stemming from social media use. Social media

Research paints two different pictures of the effects of social media: One illustrates social media as a budding resource of positive effects on the psyche (e.g., boosting self-worth, self-integrity, \& self-esteem; Gentile et al., 2012; Toma \& Hancock, 2013); the other offers a darker, more negative outlook (e.g., social media negatively affecting emotional states; Sagioglou \& Greitemeyer, 2014). When we evaluate the specific outcomes examined, however, it appears that the extent to which researchers Have investigated psychological factors does not extend far past basic positive and negative emotions. Measures used in previous studies (e.g., the Positive and Negative Affect Schedule), although emotionally related, may not be clinically relevant measures. For example, how the research related to social media and positive and negative emotions extends to clinical psychological disorders such as depression has been examined in only two studies, which did not include FoMO (Moreno et al., 2011; Steers, Wickham, \& Acitelli, 2014). Additionally, while the psychological impact of social media has been examined, cognitive factors and physical health outcomes have gone almost completely unexamined.

\subsection{PSYCHOLOGICAL CORRELATES OF FOMO:}

Whereas the above-surveyed studies have focused on the impact of social media use on psychological outcomes, such as well-being, a recent study (Przybylski et al., 2013) examined possible potential personal predictors of social media engagement, in particular aspects of deficits in psychological need satisfactions. Drawing on the selfdetermination theory (SDT; Deci \& Ryan, 1985, 2008), Przybylski et al. contend that FoMO could serve as a mediator linking deficits in psychological needs to social media engagement. Their study's results indicated that individuals who evidenced less satisfaction of the basic psychological needs for competence (efficacy), autonomy (meaningful choice), and relatedness (connectedness to others) also reported higher levels of FoMO. In the field of educational psychology, the psychological construct of motivation for learning, is one of the most highly studied variables, and has been extensively investigated in previous research (Donche et al., 2014; Linnenbrink \& Pintrich, 2002; Ratelle et al., 2007). Therefore, in the context of higher education, the SDT regarding learning motivation appears to be a particularly useful perspective to empirically explore FoMO.

Previous studies on learning motivations have placed an emphasis on the motivation behind the choices that students make, and on how social factors affect their sense of volition and initiative, as well as their well-being and 
the quality of their academic performance (Linnenbrink \& Pintrich, 2002; Ratelleet al., 2007). The SDT defines intrinsic and extrinsic sources of motivation. Intrinsic motivation refers to internal factors, such as enthusiasm and pleasure experienced while engaging in a task. In contrast, extrinsic motivation refers to external factors, such as obtaining good grades or passing exams. Studies on the quality of motivation (e.g., Donche et al., 2014) suggest that although basically distinguished as intrinsic and extrinsic, it can be further refined by making a distinction between autonomous and controlled motivation. Studies assessing the connections between these motivations, learning strategies and achievements have associated controlled motivation with surface processing and weak coping strategies in the case of failing (Ryan \& Connell, 1989). The surface approach to learning is based on an intention that is extrinsic to the real purpose of the task (Biggs, 2001). One of the most common strategies for the surface approach is rote learning content without understanding, in order to subsequently reproduce the material.

\section{METHODOLOGY}

Aim of this study is to examine the relationship between FOMO, Social Media Addiction, Aggression and Anxiety among Indian young adults.

\subsection{HYPOTHESIS}

$\mathrm{H}_{1}$ : There is a significant association between FOMO, Social Media Addiction and Psychologically relevant health outcomes such as Aggression and Anxiety.

\subsection{SAMPLE}

Purposive sampling method was used. Since the sample was young adults, participant between the age group of 18-25 years were contacted individually. Informed consent was obtained from each participant before initiating research. Sample Data was collected from 600 undergraduate and postgraduate students through google form and offline questionnaire distribution method from university students of Indian Institute of Technology, Gandhinagar (Gujarat), Gujarat Forensic Sciences University, Gandhinagar (Gujarat), Institute of Advance Research, Gandhinagar (Gujarat), Delhi University (Delhi), Amity University (Delhi NCR), AIIMS (Delhi), VIT Vellore and Dr Hari Singh Gaur University, Sagar (Madhya Pradesh).

\subsection{TOOLS}

The socio demographic datasheet was prepared to obtain demographic variables. Enquiries were made regarding name, age, gender, education, social media details, email id, number of social media friends and number of real-life friends, domicile, user name of social media account.

\subsection{SCREENING MEASURES}

Sample Data was collected using a questionnaire aimed at measuring the student's Social Media Addiction, Fear of Missing Out, Anxiety and Aggression.

\subsection{PROCEDURE}

A total of 600 participants were contacted individually from university students. The questionnaires were administered by researcher to the participants in the classrooms in which they studied without the instructor being present. The purpose of the study was explained as examining Fear of missing out, social media engagement and its correlation with anxiety and depression. Prior to obtaining participants' consent, it was specified that the questionnaire was anonymous and that no pressure would be applied should they choose to return the questionnaire unfilled or incomplete. Debriefing information was sent to the participants on the completion of the study via electronic mail, in which they could raise questions. Finally, participants were assured that no specific identifying information about the subjects will be made public. 


\section{RESULTS}

SPSS 16.0 (Statistical Package for Social Science) was used to analyze the obtained data. All the statistical test was considered significant at $\mathrm{p}<0.05$. Descriptive as well as inferential statistics were used to analyze the data. SocioDemographic data such as age, gender, domicile, Real life friends and Social Media Friends were analyzed using mean and standard deviation and gender, relationship status were analyzed using frequency. Screening measures of FOMO, Social Media Addiction, Aggression and Anxiety were described in terms of mean, standard deviation. Further Pearson Correlational analysis was done to examine relationship between FoMO, Social Media Addiction, Aggression. and Anxiety. Multiple stepwise regression analysis was used to asses relative contribution of gender, age, FoMO, social media addiction, aggression and anxiety.

Results were divided into the following sections:

Section 1: Socio Demographic Details

Section 2: Relationship between FoMO. Social Media Addiction, aggression and Anxiety.

Table 1: Descriptive Statistics of FoMo and Psychological Factors

\begin{tabular}{|c|c|c|}
\hline Factors & Mean & Std. Deviation \\
\hline Fear of Missing Out (FOMO) & 6.60 & 3.347 \\
\hline Social Media Addiction (SM) & 14.09 & 4.707 \\
\hline Personal Relationship (PR) & .76 & .818 \\
\hline Aggression Factor 1(AGG1) & 20.21 & 5.240 \\
\hline Aggression Factor 2(AGG2) & 16.89 & 4.881 \\
\hline Aggression Factor 3(AGG3) & 24.20 & 5.701 \\
\hline Aggression Factor 4(AGG4) & 26.57 & 5.839 \\
\hline Anxiety & 43.21 & 10.993 \\
\hline
\end{tabular}

Table 2: Correlation between FoMo and Psychological Factors

\begin{tabular}{|c|c|c|c|c|c|c|c|c|}
\hline & FOMO & SM & PR & AGG1 & AGG 2 & AGG 3 & AGG4 & ANXIETY \\
\hline FOMO & - & $0.128^{* *}$ & 0.078 & $0.086^{*}$ & -0.074 & $-0.113^{* *}$ & -0.229 & $-0.099^{* *}$ \\
\hline SM & $-0.128^{* *}$ & - & $-0.221^{*}$ & 0.011 & -0.061 & $0.0146^{*}$ & $-0.011^{* *}$ & -0.048 \\
\hline PR & 0.078 & $-0.221^{* *}$ & - & -0.003 & $0.088^{*}$ & -0.040 & 0.029 & $0.002^{* *}$ \\
\hline AGG1 & $-0.086^{*}$ & 0.011 & $-0.003^{*}$ & - & $0.110^{* *}$ & $0.115^{* *}$ & $0.164^{*}$ & $0.165^{* *}$ \\
\hline AGG2 & -0.074 & 0.061 & 0.088 & 0.0110 & - & $0.0134^{* *}$ & $0.0244^{* *}$ & $0.0220^{* *}$ \\
\hline AGG3 & $-0.0113^{*}$ & $0.146^{* *}$ & -0.040 & $0.115^{*}$ & $0.134^{*}$ & - & $0.0221^{* *}$ & $0.0211^{* *}$ \\
\hline AGG4 & $-0.229^{* *}$ & $-0.11^{*}$ & 0.029 & $0.164^{* *}$ & $0.178^{* *}$ & $0.224^{* *}$ & - & $0.276^{*}$ \\
\hline ANXIETY & $-0.99^{* *}$ & $-0.048^{*}$ & $0.002^{*}$ & $0.165^{*}$ & $0.062^{* *}$ & $0.220^{* *}$ & $0.277^{* *}$ & - \\
\hline
\end{tabular}

$* *$. Correlation is significant at the 0.01 level (2-tailed).

*. Correlation is significant at the 0.05 level (2-tailed).

\section{DISCUSSION}

A total of 600 sample were selected for the study, out of which 269 are female and 331 are male and they were highly educated. This is because the sample was collected from the university students. The highest percentage sample data belongs to the age group of 22 years followed by age group of 23 years, 21 years, 24 years, 20 years and 25 years. $98.7 \%$ of the sample data belongs to the urban area compare to the $1.3 \%$ of the belongs to the rural area.

Majority of the sample data had more friends on social media than the real life. Amongst them majority of the sample data have never meet majority of their social media friends. $89 \%$ of the sample data had no idea about majority of their social media friends. They don't know each other. Out of $89 \%$ of the sample data $83 \%$ sample had never talked to majority of their social media friends ever.77.8\% sample population had once or twice had a conversation with the social media friends but they have never meet each other.

Out of male and female $83 \%$ female had no idea about majority of their social media friends while $86.3 \%$ of male had no idea about the social media friends. $47 \%$ of the male agreed that they accept the friend request of the random people while $31.3 \%$ of the female also accept the friend request of the random people. 
Few participants accepted that they accept the friend request just to increase the number of friends in their profile. Also 3.4\% of the sample population had zero real life friends with whom they can spend some quality time.

$67.9 \%$ of the sample data had less than 10 real life friends while $23.3 \%$ had less than 5 real life friends. . Out of $67.9 \% 62.3 \%$ belongs to the category of male while $37.7 \%$ belongs to the category of female. Out of $23.3 \% 77.1 \%$ are male while $22.9 \%$ are female.

$69.8 \%$ of the sample population belonging to the age group of 22 years had more unknown friends in their social media account than the others. Out of $69.8 \%, 73.7 \%$ are male and $22.3 \%$ are female. Sample population belonging to the age group of 23years had more known friends in their social media account compare to the other age groups sample population.

In the present study, significant relationship was found between FoMO, Social Media Addiction, Personal Relationship, Aggression factor 1,2,3 and 4 and Anxiety.

A positive significant correlation had been obtained between FoMO and Social media addiction, Aggression factor 1 and 2 with significant level of $0.001,0.001$ and 0.005 respectively. Further, FoMO was also detected with a significant negative correlation with aggression factor 2 with significance level of 0.005 .

Significant positive correlation had been obtained between Social Media Addiction and Aggression factor 3 with significance level of 0.001 while, Social Media Addiction also had a significant negative correlation with FoM0, Personal relationship and aggression factor 2 with significance level of 0.001,0.005,0.005 respectively.

Personal Relationship had negative significant correlation with Social Media Addiction and aggression factor 3 with significance level of 0.001 and 0.005 respectively. A positive significant correlation is also obtained with aggression factor 3 at significance level 0.005 .

Aggression Factor 1 had positive significant correlation with aggression factor 2 and aggression factor 3 at significance level 0.001. A negative significant correlation had been also obtained with FoMO and Personal Relationship with significance level 0.005 and 0.001 respectively.

Aggression factor 2 had positive significant correlation with Personal Relationship, Aggression Factor 1 and Aggression Factor 3 at significance level $0.005,0.001$ and 0.001 respectively.

Aggression factor 3 had positive significant correlation with Social Media Addiction, Aggression factor 1 and Aggression Factor 3 at significance level $0.001,0.001$ and 0.005 respectively. A negative significant correlation had been obtained between aggression factor 3 with FoMO at significance level 0.001 .

Aggression factor 4 had positive significant correlation with Aggression factor 1, 2 and 3 at significance level $0.001,0.001$ and 0.005 respectively. A negative significant correlation was also obtained between Aggression Factor 4 and FoMO at significance level 0.001.

\section{CONCLUSION}

Significant positive correlation was found between Fomo, Social media Addiction, Aggression factor one, two, three, four and Anxiety. With the help of event related potential setup specific area and probe can be identified .It can be also studied further on the scale of depression FoMo leads to and probability of the person committing any crime due to the effect of depression or showing suicidal symptoms.

\section{SOURCES OF FUNDING}

None.

\section{CONFLICT OF INTEREST}

None.

\section{ACKNOWLEDGMENT}

We thank our colleagues who provided insight and expertise that greatly assisted the research. The authors received no financial support for the research, authorship, and/or publication of this article. 
Priyanka Kacker, and Saket Saurav

\section{REFERENCES}

[1] Alt, D. (2015). College students' academic motivation, media engagement and fear of missing out. Computers in Human Behavior, 49, 111-119. http://dx.doi.org/10.1016/j.chb.2015.02.057

[2] Baumeister, R. F., \& Leary, M. R. (1995). The need to belong: Desire for interpersonal attachments as a fundamental human motivation. Psychological Bulletin, 117, 497-529. http://dx.doi.org/10.1037/ 00332909.117.3.497.

[3] Blease, C. R. (2015). Too many 'friends,' too few 'likes'? Evolutionary psychology and 'Facebook depression.' Review of General Psychology, 19, 1-13. http://dx.doi.org/10.1037/gpr0000030

[4] Brown, K. W., \& Ryan, R. M. (2003). The benefits of present: Mindfulness and its role in psychological wellbeing. Journal of Personality and Social Psychology, 84, 822-848.

[5] Cañas, J., Quesada, J. F., Antolí, A., \& Fajardo, I. (2003). Cognitive flexibility and adaptability to environmental changes in dynamic complex problem- solving tasks. Ergonomics, 46, 482-501. http://dx.doi.org/10.1080/0014013031000061640.

[6] Alt, D. (2015). College students' academic motivation, media engagement and fear of missing out. Computers in Human Behavior, 49, 111-119. doi:10.1016/j. chb.2015.02.057

[7] Andreassen, C. S. (2015). Online Social Network Site Addiction: A Comprehensive Review. Current Addiction Reports, 2(2), 175-184. doi:10.1007/s40429-015- 0056-9

[8] Baker, D. A., \& Algorta, G. P. (2016). The relationship between online social networking and depression: a systematic review of quantitative studies. Cyberpsychology, Behavior, and Social Networking, 19(11), 638648. doi:10.1089/cyber.2016.0206

[9] Baumeister, R. F., Brewer, L. E., Tice, D. M., \& Twenge, J. M. (2007). Thwarting the need to belong: Understanding the interpersonal and inner effects of social exclusion. Social and Personality Psychology Compass, 1(1), 506-520.

[10] Hassanzadeh, R.\& Rezaei, A. (2011). Effect of sex, course and age on SMS addiction in students. Middle-East Journal of Scientific Research, 10 (5), 619-625. IDOSI Publications Chou, H.-T. G., \& Edge, N. (2012). «They are happier and having better lives than I am»: the impact of using Facebook on perceptions of others' lives. Cyberpsychology, Behavior and Social Networking, 15(2), 117-21. doi:10.1089/cyber.2011.0324

[11] JWT Intelligence (2011). Fear of Missing Out. Retrieved May 10, 2013, from http://www.jwtintelligence.com/production/FOMO_JWT_TrendReport_May2011.pdf

[12] Leung, L. (2008). Leisure boredom, sensation seeking, self-esteem, addiction symptoms and patterns of mobile phone use. In E. Korini, S. Utz, M. Tanis, \& S. Barnes (Eds.), Mediated interpersonal communication, 359-381. New York: Routledge.

[13] Goldin, P. R., \& Gross, J. J. (2010). Effects of mindfulness- based stress reduction (MBSR) on emotion regulation in social anxiety disorder. Emotion, 10, 83-91. http://dx.doi.org/10.1037/a0018441.

[14] Hodkinson, C. S., \& Poropat, A. E. (2014). Chinese students' participation: The effect of cultural factors. Education \& Training, 56, 430-446. http:// dx.doi.org/10.1108/ET-04-2013-0057

[15] J. Walter Thompson Intelligence. (2011). Fear of missing out (FOM0). Retrieved from https://www .jwt.com/en/worldwide/news/fomojwtexploresfear of missing out phenomenon/

[16] Kross, E., Berman, M. G., Mischel, W., Smith, E. E., \& Wager, T. D. (2011). Social rejection shares somatosensory representations with physical pain. Proceedings of the National Academy of Sciences, USA, 108, 6270-6275. http://dx.doi.org/10.1073/

[17] Sagioglou, C., \& Greitemeyer, T. (2014). Facebook's emotional consequences: Why Facebook causes a decrease in mood and why people still use it. Computers in Human Behavior, 35, 359 -363. http://dx.doi.org/10.1016/j.chb.2014.03.003

[18] Steers, M. L. N., Wickham, R. E., \& Acitelli, L. K. (2014). Seeing everyone else's highlight reels: How Facebook usage is linked to depressive symptoms. Journal of Social and Clinical Psychology, 33, 701-731. http://dx.doi.org/10.1521/jscp.2014.33.8.701.

[19] JWT Intelligence (2011). Fear of Missing Out. Retrieved May 10, 2013, from http://www.jwtintelligence.com/production/FOMO_JWT_TrendReport_May2011.pdf

[20] Katz, J.E. (1997). Social and organizational consequences of wireless communications: a selective analysis of residential and business sectors in the United States. Telematics and Informatics 14 (3), 223-256. 
[21] Leung, L.\& Wei, R. (2000). More than just talk on the move: Uses and gratifications of the cellular phone. Journalism \& Mass Communication Quarterly, 77(2), 308-320.

[22] Leung, L. (2008). Leisure boredom, sensation seeking, self-esteem, addiction symptoms and patterns of mobile phone use. In E. Korini, S. Utz, M. Tanis, \& S. Barnes (Eds.), Mediated interpersonal communication, 359-381. New York: Routledge.

[23] Ling, R. (2000). 'We will be reached:' the use of mobile telephony among Norwegian youth. Information Technology and People, 13 (2), 102-120.

[24] Ling, R. (1995). Folk perceptions of new telephone technology. FoU rapport 60/95. Kjeller, Telenor

[25] Ling, R. (2004). The Mobile Connection: The Cell Phone's Impact on Society. San Francisco, CA: Morgan Kaufmann.

[26] Nielsen (2012). Double vision - global trends in tablet and smartphone use while watching tv. Retrieved May 31, 2013, from http://www.nielsen.com/us/en/newswire/2012/double-vision-global-trends-in-tabletand-smartphone-use-while-watching-tv.html

[27] Oulasvirta, A., Rattenbury, T., Ma, L.\& Raita, E. (2011). Habits make smartphone use more pervasive. Personal and Ubiquitous Computing, 1-10.

[28] Rosen, L (2012). Helping Your Children Study Amidst Distracting Technologies. Retrieved from: http://www.huffingtonpost.com/dr-larry-rosen/kids-and-technology_b_2101414.html

[29] Stangor, C. (2010). Research methods for the behavioral sciences (Fourth edition). Measuring and describing. US: Wadsworth Pub. Co.

[30] Ten Holt, J.C., van Duijn, M.A. J. \& Boomsma, A. (2010) Scale construction and evaluation in practice: A review of factor analysis versus item response theory applications. Psychological Test and Assessment Modeling, 52 (3), 272-297.

[31] The Mobile Consumer. (2013, February) Retrieved from http://www.nielsen.com/content/dam/corporate/us/en/reports-downloads/2013\%20Reports/MobileConsumer-Report-2013.pdf 